\title{
Vitirifiye Embriyo Transfer Sikluslarında Artifisyel Endometrial Hazırlıkta Östrojen Takviyesinin Kısa Süre Kullanımı ile Reprodüktif Sonuçlar Arasındaki İlişki
}

\author{
Effect of Shorter Duration of Estrogen Replacement on the Outcome of \\ Vitrified Warmed Embryo Transfer Cycles
}

\author{
Ayşen BOZA ${ }^{1}$, Ece AKSAKAL ${ }^{2}$ \\ Mehmet CEYHAN ${ }^{2}$, Oğuzhan BULDUK ${ }^{2}$, Başak BALABAN ${ }^{2}$, Bülent URMAN ${ }^{2}$
}

1. VKV Amerikan Hastanesi, Kadın Sağlı̆̆ ve Üremeye Yardımcı Yöntemler Ünitesi, İstanbul, Türkiye

2. VKV Amerikan Hastanesi, Kadın Sağlığı ve Üremeye Yardımcı Yöntemler Ünitesi, Embryoloji, İstanbul, Türkiye

\section{$\ddot{O Z E T}$}

Amaç: Vitrifiye embriyo transfer (VET) sikluslarinda progesteron $(P)$ desteği öncesi östradiyol $(O \ddot{O})$ kullanım süresinin canlı doğum oranını (CDO) etkileyip etkilemediğini değerlendirmek.

Gereçler ve Yöntem: Bu retrospektif kohort çalıșma, Ekim 2015 ve Ekim 2017 arasında Amerikan Hastanesi Üremeye Yardımcı Teknikler Ünitesi'nde GnRH agonist uygulamasiz artifisyel endometriyum hazırlığ lile tek blastokist transferi yapllan tüm hastalari kapsamaktadir. Sadece G1 ve G2 iyi kalitede blastokistler dondurulmustur. $>43$ yas olanlar, tedavi siklus kayıtlarında eksik verileri olan veya takipten çıkan hastalar çalışma dışı bırakılmıştır. Tüm hastalara âdetin 2. günü $6 \mathrm{mg}$ sabit dozdan oral Ö tedavisi başlanmıştır. Östradiyol kullanım süresi embriyo transfer (ET) günü planlamasina göre 8 ile 14 gün arası değişmektedir. Toplamda 241 hastanın VET siklusu Ö kullanım sürelerine göre (Grup 1: <12 gün, $n=105$; Grup 2: $\geq 12$ gün, $n=136$ ) analiz edilmiştir. Çalışmanin primer sonuç değisskeni CDO'dir.

Bulgular: Toplam 241 VET siklusundaki P kullanımı öncesi E kullanım süresi: 8 gün (\%3), 9 gün (\%8), 10 gün (\%16), 11 gün (\%16.5), 12 gün (\%22.5), 13 gün (\%20.5), 14 gün (\%13.5) şeklinde dağıllım göstermektedir. Östradiyol takviyesinin 12 günün altında kullanımının 12 gün üzerinde kullanımına kıyasla CDO üzerine anlaml etkisi yoktur $(O R=1.25$; \%95 CI [0.75-2.1], $p=0.38$ ). Klinik gebelik, erken ve fetal kayı oranlarl da gruplar arasında benzerdir. Ortalama endometrial kalınlı gruplar arasinda benzerdir $(9.5 \mathrm{~mm})$. Östradiyol takviyesinin reprodüktif sonuçlarla ilişkisi her gün için ayrı ayrı değerlendirildiğinde de anlamlı bir fark saptanmamıştır.

Sonuç: Vitrifiye embriyo transfer sikluslarında genel kabul görenden daha kısa östradiyol kullanımı canlı doğum oranlarını etkilememekte, abort riskini artırmamaktadir. Bu durum test edilmemis ancak kuvvetle kabül görmüş bu protokolü sorgulanir kılmaktadır.

Anahtar Kelimeler: blastokist, vitrifiye, embriyo transferi, östrojen, endometriyum

\section{ABSTRACT}

Objective: To evaluate the effect of a shorter duration of estradiol (E) exposure prior to progesterone $(P)$ administration on live birth rate (LBR) in vitrified warmed embryo transfer (VWET) cycles.

\section{İletişim}

Sorumlu Yazar: Ayşen BOZA, Dr.

Adres: Amerikan Hastanesi, Teşvikiye, Güzelbahçe Sk. No: 20, 34365 Şişli, İstanbul, Türkiye

E-Posta: aysenboza@hotmail.com

Tel: +90 (212) 4443777

Makale Geliş: 28.10.2019

Makale Kabul: 25.11.2019

DOI: http://dx.doi.org/10.16948/zktipb.639155
Material and Methods: A retrospective cohort study was conducted in the American Hospital (Koc University affiliated private hospital) between October 2015 and October 2017. All VWET cycles with a single blastocyst transfer using artificial endometrial preparation without GnRH agonist pretreatment were included. Only G1 and G2 good quality blastocysts had been cryopreserved. Women $>43$ years of age, treatment cycles with incomplete data and women who were lost to follow-up were excluded. All women received oral E treatment starting on day 2 of menstrual bleeding in a fixed dose of $6 \mathrm{mg} /$ day. The duration of $E$ administration varied from 8 to 14 days due to concerns regarding embryo transfer scheduling. A total of 241 patients with vitrified warmed single blastocyst transfer cycles were analyzed according to the duration of $E$ administration (Group 1: $<12$ days, $n=105$; Group 2: $\geq 12$ days, $n=136$ ). The main outcome measure was LBR per transfer.

Results: Among a total of 241 patients with vitrified warmed blastocyst transfers, E exposure prior to P supplementation was as follows: 8 days (3\%), 9 days (8\%), 10 days (16\%), 11 days (16.5\%), 12 days $(22.5 \%), 13$ days $(20.5 \%), 14$ days $(13.5 \%)$. $L B R$ was not significantly affected when the E treatment was administered for less than 12 days $(O R=1.25$; 95\%CI [0.752.1], $p=0.38)$. Mean endometrial thickness was similar among the groups $(9.5 \mathrm{~mm})$. When the patients were sub-divided according to the duration of E treatment, primary and secondary outcomes were likewise similar.

Conclusion: Shorter than the normally accepted duration of $E$ administration yields similar LBRs in VWET cycles, thus questioning the need to adhere strictly to an untested protocol.

Keywords: blastocyst, vitrification, embryo transfer, estrogen, endometrium

\section{GíRiş}

Son yıllarda yardımcı üreme yöntemlerinde vitrifiye embriyo transferi (VET) ni yaygınlaştıran gelişmeler yaşandi. Kriyoprezervasyon ve çözme tekniklerindeki ilerlemeler, tüm embriyoların dondurulup transferin sonraki siklusa ertelendiği yaklaşımların artan oranda benimsenmesi bu gelişmelerin başında gelmektedir (Kupka et al., 2016).

Normo-ovulatuar kadınlarda endometriyum overden üretilen hormonlar tarafindan hazırlanır; endometriyum estrojen etkisi altında proliferatif değişiklikler geçirdikten sonra progesteron $(\mathrm{P})$ etkisi ile endometrial maturasyon başlar ve sekretuar duruma geçer (Makker \& Singh, 2006). VET sikluslarında endometriyumu embriyo açısından elverişli bir hale getirebilmek için doğal siklus takibi, ovaryan stimulasyon veya artifisyel olarak hormon takviyesi kullanılan yöntemlerdir. Randomize kontrollü çalışmalarda bu protokollerinin birinin diğeri- 
ne üstünlügü gösterilememiştir (Ghobara, Gelbaya, \& Ayeleke, 2017).

Artifisyel endometrial hazırlikta (AEH) östrojenizasyon, embriyoların transfer edileceği siklusun 1. günü başlanan oral veya transdermal östradiyol (Ö) takviyesi ile sağlanır. Donasyon siklusları AEH'ın en sık kullanıldığ 1 sikluslardır. Bir çalışmada 11 günden az Ö takviyesinde abort oranlarının arttığ1, 40 günden fazla kullanımında ise kırılma kanamalarının yaygın olduğu bildirilmiştir (Borini et al., 2001). Farklı dozlarda ve sürelerde kullanılan Ö takviyesinin uterin reseptivitede anahtar rol oynadığı ileri sürülmektedir (Ma, Song, Das, Paria, \& Dey, 2003; Simon, Domínguez, Valbuena, \& Pellicer, 2003). Klinik kullanımda P öncesi kullanılan Ö takviyesi her hasta için farklı olabilirken, takviye süresinin alt ve üst limiti halen tartışmalıdır. Donasyon sikluslarında Ö takviyesi için en uygun süreyi değerlendiren çalışmalarda verilen gebelik oranları birbiriyle çelişmektedir (Borini et al., 2001; S.Sunkara, S.Seshadri, \& T.El-Toukhy, 2011). Otolog VET sikluslarında Ö takviyesinin üst limiti güncel retrospektif bir çalışmada CDO açısından değerlendirilmiş ve 21 günün altı kullanıma kıyasla 28 günden uzun kullanımda gebelik oranları düşerken 35 günden uzun kullanımda erken gebelik kayıplarının arttığ1 gözlenmiştir (Bourdon et al., 2018). Bu olumsuz etkinin ekzojen Ö'nin önerilenden daha kısa kullanımda ortaya çıkıp çıkmadığı bilinmemektedir.

$\mathrm{Bu}$ çalışmanın amacı, tek blastokist transferi yapılan otolog VET sikluslarda Ö takviyesinin kısa süre kullanımın CDO üzerine etkisini değerlendirmektir.

\section{GEREÇ ve YÖNTEM}

\section{Çalışma populasyonu}

$\mathrm{Bu}$ retrospektif kohort çalışmada, Ekim 2015 ve Ekim 2017 arasında Amerikan Hastanesi Üremeye Yardımcı Teknikler Ünitesi'nde pituiter baskılamasız AEH ile tek blastokist transferi yapılan tüm hastalar değerlendirilmiş̧ir. Yaşı $>43$ yaş olanlar, kayıtlarında eksik verileri olan veya takipten çıkan hastalar çalışma dışı bırakılmış̧ır. Toplamda 241 hastanın VET siklusu Ö kullanım sürelerine göre (Grup 1: <12 gün, $n=105$; Grup 2: $\geq 12$ gün, $n=136$ ) analiz edilmiştir. Çalışmanın primer sonuç değişkeni CDO'dır.

\section{Embriyo kültür, kryoprezervasyon ve çözme}

Embriyo kültürü $\% 5 \mathrm{O}_{2}$ konsantrasyonunda gerçekleştirilmiştir (Nastri et al., 2016). Blastokist skorlamas1 Dokras skorlama sistemine göre yap1lmıştır (Balaban, Yakin, \& Urman, 2006; Van Den Abbeel et al., 2013) Birinci kalite blastokist; iç hücre kütlesi önce merkezin dışında sıralanan, sonra ekspansiyona uğrayarak erken kavitasyon oluşturabilen embriyodur. Ikinci kalite blastokist; tekli veya çoklu vakuollerin izlendiği bir geçici faz durumudur; gelişim hızı 1.kalite blastokiste göre daha yavaştır. Üçüncü kalite blastokist; iç hücre kütlesinde koyu ve nekrotik görülen hücrelerle karakterize birden çok dejeneratif alanın olduğu embriyodur. Birinci ve ikinci kalite blastokistler daha hızlı gelişen, ekspansiyonunu hızlı tamamlayan embriyolardır.

Vitrifikasyon işlemi Cobo et. al.'un tanımladığ1 protokole göre yapılmaktadır (Cobo et al., 2012). Kisaca, blastokist vitrifikasyonunda etilen glikol ve DMSO (dimetilsülfoksit) bazlı bir vitrifikasyon solüsyonu, açık sistem taşıyıcı aparat eşliğinde gerçekleştirilmiştir. Dondurulacak blastokistler öncelikle 12 dakika boyunca \% $7.5(\mathrm{v} / \mathrm{v})$ luk etilen glikol, \%7.5lik DMSO+TCM 199 ve \%20 sentetik serum içeren solüsyonda dengelenir. Vitrifikasyon aşamasında ise $\% 15$ etilen glikol, $\% 15$ DMSO ve 0.5 $\mathrm{mol} / \mathrm{l}$ sükroz içeren ikinci solüsyonu alınıp yaklaşık 30-45 sn bekletilerek, 10 saniye içerisinde taşı1ıı aparata yüklenir. Tüm bu işlemler oldukça hızlı ve süreye bağımlı olarak yapılmalıdır.

Çözme işlemine ilk olarak çözülecek blastokistler $37^{\circ} \mathrm{C}$ de $1.0 \mathrm{~mol} / \mathrm{L}$ sükroz ve $\% 20^{\prime}$ lik sentetik serum içeren TCM199 solüsyonu içerisinde $1 \mathrm{dk}$. bekletilerek başlanır, embriyolar oda sıcaklığındaki $0.5 \mathrm{~mol} / \mathrm{L}$ sükroz ve $\% 20$ 'lik sentetik serum içeren TCM 199 solüsyona aktarılıp 3 dakika bekletilir ve son olarak \%20'lik sentetik serum içeren TCM 199 solüsyonunda yıkanarak kültür ortamına alınır.

\section{Embriyo transferi öncesi AEH}

Tüm hastalara âdetin 2. veya 3. günü $6 \mathrm{mg}$ sabit dozdan oral Ö (Estrofem, Novo Nordisk, Denmark) tedavisi başlanmıştır. Östradiyol kullanım süresi ET günü planlamasına göre 8 ile 14 gün arası değişmektedir. Hastalar belirlenen Ö kullanım süresinin bitiminde kliniğe çağrılarak transvaginal ultrasonografi ile endometriyum kalınlığ ve paterni değerlendirilmiştir. Endometriyumu $7 \mathrm{~mm}$ altında olan hastalarda kliniğin yaklaşımı aynı doz Ö ile takviye süresinin uzatılması ve/veya transdermal Ö eklenmesi veya siklusun iptal edilmesidir. Uzatılan takviye süresi sonrasi endometriyumu halen $7 \mathrm{~mm}$ altında olan ancak trilaminar paterni olan hastalarda ET planlamas1 yapılır; olmayanlarda AEH siklusu iptal edilir. Bu çalışmaya sadece aynı doz oral Ö ile takviye süresi uzatılan ve transfere karar verilen hastalar dâhil edilmiştir. Embriyo transferine karar verilen hastalara vaginal P (Crinone $8 \%$ gel, 90mg, Merck Serono, Switzerland) başlanmış ve 5 günlük kullanım sonrasında 6. gün ET gerçekleştirilmiştir. Gebelik test sonucu pozitif olan hastalar aynı ilaçlar1 12.haftaya kadar kullanmaya devam etmişlerdir.

\section{İSTATISTIKKSEL ANALIZ}

Hastaların genel özellikleri, embriyolojik özellikleri ve siklus sonuçlarına dosya kayıtlarından ulaşılmıştır. Dosya kayıtlarındaki eksiklikler hastalar aranarak tamamlanmıştır. Çalışmanın primer sonuç ölçütü 22 hafta ve üzeri canlı doğan bebekleri tanımlayan CDO'dır. Klinik gebelik (ultrasonografide intrauterin gestasyonel kese görünmesi), erken kayıp (10 hafta alt1 gebelik kayb1), fetal kayıplar (10-19 hafta arası gebelik kaybı) da ayrıca değerlendirilmiştir (Silver, Branch, Goldenberg, Iams, \& Klebanoff, 2011).

Veriler IBM ${ }^{\circledR}$ SPSS ${ }^{\circledR}$ Statistics Versiyon 20.0 (SPSS Inc. Headquarters, USA) ile değerlendirildi. $\mathrm{P}$ değeri $<0.05$ istatistiksel anlamlılık olarak kabul edildi. Kantitatif değişkenler Mann Whitney 
U testi ile niteleyici değişkenler Pearson X2 veya Fisher exact test ile değerlendirildi. Primer ve sekonder sonuç ölçütleri ile ilgili potansiyel karıştırıcılar (yaş, embriyo kalitesi, over yanıtı, geçmiş in vitro fertilizasyon siklusu say1s1) logistik regresyon ile değerlendirildi ve sonuçlar odds oranı (OO) ve $\% 95$ güven aralığı (\%95 GA) ile verildi.

\section{BULGULAR}

Toplam 241 hastanın VET siklusundaki $\mathrm{P}$ kullanımı öncesi Ö takviye süresi: 8 gün (\%3), 9 gün $(\% 8), 10$ gün $(\% 16), 11$ gün $(\% 16.5), 12$ gün $(\% 22.5), 13$ gün $(\% 20.5), 14$ gün $(\% 13.5)$ şeklinde dağ 1 lım göstermektedir. Hastaların \%43.6 $(n=105)$ 's $<12$ gün (Grup 1); \%56.4 ( $n=136)$ 'ü $\geq 12$ gün (Grup 2) Ö takviyesi almıştır. Demografik özellikler açısından gruplar arasından herhangi bir fark yoktur (Tablo 1). Embriyolojik özelliklerine bakıldığında dondurulan total embriyo sayısı ve transfer edilen blastokist kaliteleri benzerdir. Progesteron başlamadan hemen önce bakılan ortalama endometrial kalınlık, endometrial patern, ET kolaylığı açısindan gruplar arasinda fark yoktur (Tablo 1).

Tablo 1: Demografik ve embriyolojik özellikler.

\begin{tabular}{|c|c|c|c|}
\hline \multirow[b]{2}{*}{ Yaş, yıl } & \multicolumn{2}{|c|}{$\begin{array}{c}\text { Östradiyol takviye } \\
\text { süresi } \\
<12 \text { gün }(n=105) \\
\geq 12 \operatorname{gün}(n=136)\end{array}$} & \multirow{2}{*}{$\begin{array}{l}\underset{P}{\boldsymbol{P}} \text { değeri } \\
0.9\end{array}$} \\
\hline & $33 \pm 4$ & $33 \pm 5$ & \\
\hline Vücut kütle indeksi, kg/m² & $22.5 \pm 4$ & $22 \pm 3$ & 0.7 \\
\hline Parite & $0.03 \pm 0.2$ & $0.08 \pm 0.3$ & 0.12 \\
\hline İnfertilite süresi, yıl & $1.8 \pm 1$ & $2 \pm 1$ & 0.15 \\
\hline \multicolumn{4}{|l|}{ İnfertilite endikasyonu } \\
\hline Ovulasyon bozukluğu & 20.5 & 26.5 & \multirow{7}{*}{0.18} \\
\hline Erkek faktör & 17.5 & 9 & \\
\hline Açıklanamayan & 25 & 28 & \\
\hline Düşük over rezervi & 4 & 3 & \\
\hline Endometriyozis & 11.5 & 7 & \\
\hline Tubal faktör & 6 & 3 & \\
\hline Çoklu etyoloji & 15.5 & 23.5 & \\
\hline $\begin{array}{l}\text { Toplam vitrifiye edilen } \\
\text { embriyo sayısı }\end{array}$ & $4.5 \pm 2$ & $5 \pm 2.5$ & 0.06 \\
\hline $\begin{array}{l}\text { Toplam oral östradiyol } \\
\text { dozu, mg }\end{array}$ & $60 \pm 5.5$ & $77 \pm 4.5$ & $<0.001$ \\
\hline Endometrial kalınlık, mm & $9.5 \pm 2$ & $9.5 \pm 1.5$ & 0.53 \\
\hline Endometrial patern & & & \\
\hline $\begin{array}{l}\text { Trilaminer } \\
\text { Non-trilaminer }\end{array}$ & $\begin{array}{l}51.5 \\
48.5\end{array}$ & $\begin{array}{l}44 \\
56\end{array}$ & 0.16 \\
\hline $\begin{array}{l}\text { Transfer edilen embriyo } \\
\text { kalitesi }\end{array}$ & & & \\
\hline $\begin{array}{l}\text { Grad } 1 \\
\text { Grad } 2 \\
\end{array}$ & $\begin{array}{l}13 \\
87\end{array}$ & $\begin{array}{l}16 \\
84\end{array}$ & 0.54 \\
\hline $\begin{array}{l}\text { Embriyo transferi } \\
\text { Kolay } \\
\text { Zor }\end{array}$ & $\begin{array}{l}98 \\
2\end{array}$ & $\begin{array}{l}97.8 \\
2.2\end{array}$ & 0.7 \\
\hline
\end{tabular}

Değişkenler ortalama \pm standard deviasyon veya n (\%) ile belirtilmiştir.
Değerlendirilen potansiyel karıştırıcıların sonuç ölçütlerine istatistiksel anlamlı bir etkisi saptanmamıştır (Tablo 2).

Tablo 2: Vitrifiye blastokist transferi sonrası canlı doğum oranları ile ilişkili değişkenler.

\begin{tabular}{|l|c|c|}
\hline & Odds oranı & $95 \%$ Güven Aralığ 1 \\
\hline Yumurta toplamadaki yaş >35y & 1.3 & $0.7-2.3$ \\
\hline Embriyo kalitesi & 0.8 & $0.4-1.5$ \\
\hline Overyan yanıt & 0.9 & $0.6-1.5$ \\
\hline Önceki IVF siklus sayıs1 & 0.8 & $0.6-1.1$ \\
\hline
\end{tabular}

Figür 1: Östradiyol takviyesinin 12 günün altında kullanımı 12 gün üzerinden kullanımına kıyasla CDO anlamlı düzeyde etkilenmemektedir $(\mathrm{OR}=1.25 ; \% 95 \mathrm{CI}[0.75-2.1], \mathrm{p}=0.38)$. Klinik gebelik, erken ve fetal kayıp oranları da gruplar arasinda benzerdir.

Östradiyol takviye edilen süreye göre reprodüktif sonuçlar

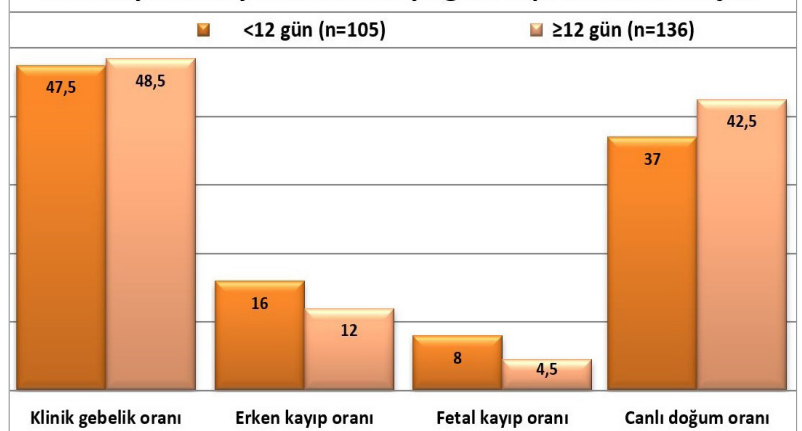

Tablo 3: Östrojen takviye günlerine göre reprodüktif sonuçların dağ1limi.

\begin{tabular}{|c|c|c|c|c|c|c|c|c|}
\hline & \multicolumn{7}{|c|}{ Östrojen takviyesi süresi } & \multirow{3}{*}{$\underset{\text { değeri }}{\mathrm{P}}$} \\
\hline & $\begin{array}{c}8 \\
\text { gün }\end{array}$ & $\begin{array}{c}9 \\
\text { gün }\end{array}$ & $\begin{array}{c}10 \\
\text { gün }\end{array}$ & $\begin{array}{c}11 \\
\text { gün }\end{array}$ & $\begin{array}{c}12 \\
\text { gün }\end{array}$ & $\begin{array}{l}13 \\
\text { gün }\end{array}$ & $\begin{array}{l}14 \\
\text { gün }\end{array}$ & \\
\hline $\begin{array}{c}\text { Hasta say1s1 } \\
n\end{array}$ & 7 & 19 & 39 & 40 & 54 & 50 & 32 & \\
\hline $\begin{array}{c}\text { Klinik gebelik } \\
\%\end{array}$ & 71.5 & 42 & 39 & 40 & 54 & 50 & 32 & 0.95 \\
\hline $\begin{array}{c}\text { Erken kayıp } \\
\%\end{array}$ & 0 & 5.3 & 25.6 & 15 & 3.7 & 20 & 12.5 & 0.90 \\
\hline $\begin{array}{c}\text { Fetal kayıp } \\
\%\end{array}$ & 0 & 10.5 & 10.5 & 5 & 0 & 12 & 0 & 0.41 \\
\hline $\begin{array}{c}\text { Canlı doğum } \\
\%\end{array}$ & 66.5 & 28 & 33 & 40.5 & 48 & 36 & 44 & 0.63 \\
\hline
\end{tabular}

Östradiyol takviyesi ile reprodüktif sonuçlar (klinik gebelik, erken kayıp, fetal kayıp, canlı doğum) arasındaki ilişki Östradiyol takviyesinin reprodüktif sonuçlarla ilişkisi her gün için ayrı ayrı değerlendirildiğinde de anlamlı bir fark saptanmamıştır (Tablo 3).

\section{TARTIŞMA}

Çalıșmamızın sonuçlarına göre dondurulup çözülmüş otolog tek blastokist transferlerinde Ô takviyesinin önerilenden daha kısa kullanımı can11 doğum oranlarını olumsuz etkilememekte; erken kayıp veya fetal kayıp riskini artırmamaktadır. VET sikluslarındaki Ö takviyesinin değerlendirildiği çalışmaların çoğu donasyon çalışmalarıdır. Bu çalışmada otolog blastokist transferinin incelenmiş olması çalışmanın genelleştirilebilirliğini, reproduktif sonuçları etkilediği düşünülen değişkenlerin univaryant analiz ile değerlendirilmesi de çalışmanın eksternal geçerliliğini artırmaktadır. Klinik pratikte VET siklusların ve tek blastokist transferinin artıș göstermesi endometrial hazırlama protokollerinin güvenilirliğini daha fazla sorgulatır olmuştur.

Başarılı bir implantasyon için kaliteli bir embriyo ve embriyonun gelişim aşaması ile eşzamanlı ve reseptif bir endometriyum gereklidir (Ma et al., 2003). Insan endometriyumu bir blastokistin implantasyonu için sadece 4-5 gün reseptiftir (Salamon- 
sen, Nie, Hannan, \& Dimitriadis, 2009) ve estrojen ve progesteron reseptivitenin oluşumunda kritik rol oynarlar (Young, 2013). Östrojen endometrial proliferasyon için gerekli olduğundan implantasyon, desidualizasyon ve erken embriyo gelişiminde ana belirleyicidir (Ramathal, Bagchi, Taylor, \& Bagchi, 2010). Fare modellerinde düşük ekzojen Ö’nin endometriyumda reseptiviteyi sağlamada etkili olmadığı, yüksek dozlarının ise endometriyumu reseptif durumdan refraktör duruma geçirebileceği gösterilmiştir (Ma et al., 2003). Güncel bir çalışmada VET siklusunda otolog blastokist transferlerinde ekzojen Ö takviyesi 28 günü geçtiğinde CDO azalabilmektedir (Bourdon et al., 2018). Bu etkinin ekzojen Ö'nin önerilenden daha kısa kullanımda ortaya çıkıp çıkmadığı bilinmemektedir. Younnis ve ark.'nın 1992'de yaptıkları 29 hastayı içeren bir donasyon çalışmasında 4-11 gün arası ekzojen Ö kullanımının 12-19 günlük kullanıma kıyasla gebelik oranını önemli miktar azalttığ 1 gösterilirken (\%7.7 vs. \%52), en uygun Ö kullanım süresinin 6-11 gün arası olduğunu, daha uzun kullanımda (12-27 gün arası) gebelik oranlarının düştüğünü gösteren çalışmalar da vardır (Michalas et al., 1996; Younis et al., 1992). Başka bir donasyon çalışmasında 10 günden az kullanımda 11-40 gün arası kullanıma kıyasla implantasyon ve gebelik oranları değişmese de abort oranlarının arttığı vurgulanmıştır (Borini et al., 2001). Bizim çalışmamızda 10 günden az kullanımda erken ve fetal kayıp oranında anlamlı bir değişiklik saptanmamıştır. Bu çalışmalar değerlendirilirken popülasyonlarının yüksek oranda heterojenite gösterdiği ve oldukça küçük hasta gruplarında yapıldığı göz önünde bulundurulmalıdır.

Çalıșmamızın sonuçlarına göre VET siklusunda tek blastokist transferinde Ö takviyesi 12 günün altında kullanılsa bile canlı doğum oranlarını değiştirmemektedir. Dolayısıyla çalışma ET günü ayarlamalarında reprodüktif sonuçlardan ödün vermeden ne kadar esnek olunabileceğine dair bir bakış aç1s1 sunmaktadir. Bu durum ET planlarken hasta ve kliniğin ihtiyaçlarına göre Ö takviye süresinin kısa tutulabileceğini göstermektedir.

Çalışmamızda gerekli önlemler titizlikle alınmış olmasına rağmen bazı eksiklik ve/veya biasler mevcuttur. Retrospektif tasarım çalışmayı bazı biaslara açık hale getirmektedir. Eksik verilerin ve reprodüktif sonuçların ayrıntısıyla hastalara telefonla ulaşılarak elde edilmesi, sonuçlarına ulaşılamayan hastaların dâhil edilmemesi çalışmadaki eksiklikleri azaltmaya yönelik alınan önlemlerdir. $\mathrm{AEH}$ protokolünün $\mathrm{E}$ takviye süresi hariç homojen olması (pitüiter baskılamasız, oral Ö ile sabit P kullanım süresi ile) tedavide ek karıștırıcıların olmamasına sağlamıştır. Vurgulanması gereken bir diğer nokta Ö takviyesinin hastaya veya hastanın siklus özelliklerine göre karar verilmediği, merkez açısından VET siklusunun fiziksel koşularının organize edilebilirliğine ve hastanın ulaşılabilirliğine göre değiştiğidir.

\section{KAYNAKLAR}

1. Balaban, B., Yakin, K., \& Urman, B. (2006). Randomized comparison of two different blastocyst grading systems. Fertility and Sterility. https://doi.org/10.1016/j.fertnstert.2005.11.013
2. Borini, A Prato L D. Bianchi, L Violini, F Cattoli, M., \& Flamigni, C. (2001). Effect of duration of estradiol replacement on the outcome of oocyte donation. Journal of Assisted Reproduction and Genetics.

3. Bourdon, M., Santulli, P., Kefelian, F., Vienet-Legue, L., Maignien, C., Pocate-Cheriet, K., ... Chapron, C. (2018). Prolonged estrogen (E2) treatment prior to frozen-blastocyst transfer decreases the live birth rate. Human Reproduction. https://doi.org/10.1093/humrep/dey041

4. Cobo, A., De Los Santos, M. J., Castellò, D., Gámiz, P., Campos, P. \& Remohi, J. (2012). Outcomes of vitrified early cleavage-stage and blastocyst-stage embryos in a cryopreservation program: Evaluation of 3,150 warming cycles. Fertility and Sterility. https://doi.org/10.1016/j. fertnstert.2012.07.1107

5. Ghobara, T., Gelbaya, T. A., \& Ayeleke, R. O. (2017). Cycle regimens for frozen-thawed embryo transfer. Cochrane Database of Systematic Reviews. https://doi.org/10.1002/14651858.CD003414.pub3

6. Kupka, M. S., D’Hooghe, T., Ferraretti, A. P., De Mouzon, J., Erb, K., Castilla, J. A., ... Goossens, V. (2016). Assisted reproductive technology in Europe, 2011: Results generated from European registers by ESHRE. Human Reproduction. https://doi.org/10.1093/humrep/dev319

7. Ma, W. ge, Song, H., Das, S. K., Paria, B. C., \& Dey, S. K. (2003) Estrogen is a critical determinant that specifies the duration of the window of uterine receptivity for implantation. Proceedings of the National Academy of Sciences of the United States of America. https://doi. org/10.1073/pnas.0530162100

8. Makker, A., \& Singh, M. M. (2006). Endometrial receptivity: Clinical assessment in relation to fertility, infertility, and antifertility. Medicinal Research Reviews. https://doi.org/10.1002/med.20061

9. Michalas, S., Loutradis, D., Drakakis, P., Kallianidis, K., Milingos, S., Deligeoroglou, E., \& Aravantinos, D. (1996). A flexible protocol for the induction of recipient endometrial cycles in an oocyte donation programme. Human Reproduction. https://doi.org/10.1093/oxfordjournals.humrep.a019297

10. Nastri, C. O., Nóbrega B. N., Teixeira, D. M.,Amorim, J., Diniz, L. M. M., Barbosa, M. W. P., ... Martins, W. P. (2016). Low versus atmospheric oxygen tension for embryo culture in assisted reproduction: a systematic review and meta-analysis. Fertility and Sterility. https:// doi.org/10.1016/j.fertnstert.2016.02.037

11. Ramathal, C. Y., Bagchi, I. C., Taylor, R. N., \& Bagchi, M. K. (2010). Endometrial decidualization: Of mice and men. Seminars in Reproductive Medicine. https://doi.org/10.1055/s-0029-1242989

12. S.Sunkara, S.Seshadri, \& T.El-Toukhy. (2011). The impact of the duration of estrogen supplementation on the outcome of medicated frozen-thawed embryo transfer (FET) cycles. Fertility and Sterility. https:// doi.org/10.1016/j.fertnstert.2011.07.163 LK - http://julac.hosted.exlibrisgroup.com/openurl/HKPU ALMA/HKPU SERVICES PAGE? si$d=E M B A S E \&$ sid $=E M B A S E \&$ issn $=00150282 \& i d=d o i: 10 . \overline{1} 016 \% 2 F j$. fertnstert. $2011.07 .163 \&$ atitle $=$ The + impact + of + the + durati on + of +estrogen + supplementation + on + the + outcome + of + medicated + frozen-thawed + embryo +transfer $+\% 28 F E T \% 29+$ cycles \& stitle $=$ Fertil. + Steril. $\&$ title $=$ Fertility + and + Sterility \& volume $=96 \& i s-$ sue $=3 \&$ spage $=S 43 \&$ epage $=\&$ aulast $=$ Sunkara \&aufirst $=S . K . \& a u i-$ $n i t=S . K . \&$ aufull $=$ Sunkara $+S . K . \&$ coden $=\& i s b n=\&$ pages $=S 43-$

13. Salamonsen, L. A., Nie, G., Hannan, N. J., \& Dimitriadis, E. (2009). Society for reproductive biology founders lecture 2009. Preparing fertile soil: The importance of endometrial receptivity. Reproduction. Fertility and Development. https://doi.org/10.1071/RD09145

14. Silver, R. M., Branch, D. W., Goldenberg, R., Iams, J. D., \& Klebanoff, M. A. (2011). Nomenclature for pregnancy outcomes: Time for a change. Obstetrics and Gynecology. https://doi.org/10.1097/AOG. ob013e3182392977

15. Simon, C., Dominguez, F., Valbuena, D., \& Pellicer, A. (2003). The role of estrogen in uterine receptivity and blastocyst implantation. Tren$d s$ in Endocrinology and Metabolism. https://doi.org/10.1016/S10432760(03)00084-5

16. Van Den Abbeel, E., Balaban, B., Ziebe, S., Lundin, K., Cuesta, M. J. G., Klein, B. M., ... Arce, J. C. (2013). Association between blastocyst morphology and outcome of single-blastocyst transfer. Reproductive BioMedicine Online. https://doi.org/10.1016/j.rbmo.2013.07.006

17. Young, S. L. (2013). Oestrogen and progesterone action on endometrium: A translational approach to understanding endometrial receptivity. Reproductive BioMedicine Online. https://doi.org/10.1016/j. rbmo.2013.06.010

18. Younis, J. S., Mordel, N., Lewin, A., Simon, A., Schenker, J. G., \& Laufer, N. (1992). Artificial endometrial preparation for oocyte donation: The effect of estrogen stimulation on clinical outcome. Journal of Assisted Reproduction and Genetics. https://doi.org/10.1007/ BF01203817 